\title{
Trochanteric Buttress Plate Combined with Proximal Femoral Nail for Unstable Intertrochanteric Fractures. [Innovative Technique]
}

\author{
Shashikant Basavraj Ganjale ${ }^{1 *}$, Wasudeo M. Gadegone², Pradeep Kothadia ${ }^{3}$ \\ ${ }^{1}$ Ashwini Sahakari Rugnalaya and Research Centre, Solapur, India \\ ${ }^{2}$ Department of Orthopedic and Traumatology, GMC, Chandrapur, India \\ ${ }^{3}$ Kothadia Trauma and Orthopaedic Center, Solapur, India \\ Email: *sbganjale_live@rediffmail.com
}

How to cite this paper: Ganjale, S.B. Gadegone, W.M. and Kothadia, P. (2018) Trochanteric Buttress Plate Combined with Proximal Femoral Nail for Unstable Intertrochanteric Fractures. [Innovative Technique]. Open Journal of Orthopedics, 8 , 235-247.

https://doi.org/10.4236/ojo.2018.86027

Received: May 13, 2018

Accepted: June 18, 2018

Published: June 21, 2018

Copyright $(9) 2018$ by authors and Scientific Research Publishing Inc. This work is licensed under the Creative Commons Attribution International License (CC BY 4.0).

http://creativecommons.org/licenses/by/4.0/

\begin{abstract}
Introduction: Proximal femoral nail is a better choice of implant for the treatment of an unstable trochanteric fracture, however it is associated with screw migration and cutout because of greater trochanteric comminution and coronal split. This study is to evaluate the results of Trochanteric Buttress Plate (TBP) combined with PFN in an unstable IT fractures for buttressing lateral wall and reinforcing fixation. Materials and Methods: We carried out a consecutive study of 32 patients of Unstable intertrochanteric fracture femur with lateral wall comminution. It was studied at Ashwini Sahakari Rugnalaya and Sanshodhan Kendra Solapur India and Government medical college Chandrapur India from April-2015 to December-2017 using innovative Trochanteric buttress plate along with PFN. Eighteen male and fourteen female in the age group of 55 to 80 years were included in the study. There were 26 cases of A3 and six cases of A2 were fixed by PFN combined with trochanteric buttress plate to augment the comminuted lateral wall. Results: The bone healing is observed in all the cases in the mean period of 12.6 weeks. Four patients developed complications, including lateral migration of neck screws ( $\mathrm{n}$ $=2)$, superficial infection $(n=2)$. Patients were followed up for a mean of 10.6 months. At the end of follow-up the Salvati and Wilson hip function was 36 (out of 40 ) in $87.5 \%$ of patients [twenty eight patients]. The clinical, radiological and functional outcomes were found to be satisfactory. Conclusion: The stabilization of lateral trochanteric wall with trochanteric buttress plate restores anatomy, increases the stability of construct and prevents inherent complication of screw migration and cutout.
\end{abstract}




\section{Keywords}

Trochanteric Buttress Plate, Lateral Wall Comminution of Greater

Trochanter, Unstable Trochanteric Fracture, Screw Migration, Cut Out of

Screw

\section{Introduction}

In an unstable trochanteric fractures intact lateral wall plays a key role instabilization of fracture by proximal femoral nail. The deficiency of lateral wall leads to excessive fracture collapse and varus malposition positioning [1] [2]. Therefore results of dynamic hip screw are far from satisfactory [3] [4]. The locking plate technology coupled with inbuilt metaphyseal contour enables fixation of trochanteric fracture using the minimally invasive plate osteosynthesis (MIPO) technique, but no superior results than DHS [5].

Intramedullary nailing has become a popular method of stabilization of unstable trochanteric fractures in adults. The nail itself gives support to posteromedial wall and resists excessive fracture collapse therefore biomechanically PFN is a better choice of implant for fixation of unstable trochanteric fractures [6].

There are some pitfalls as implant failure does occur due to unbalanced biomechanical forces acting on implant around hip joint as there is no support to lateral wall. Hence screw migration, $\mathrm{z}$ effect and cut out of the screws and implant breakage are common complications. Dynamic hip screw (DHS) with trochanteric buttress plate stabilizes the trochanteric fracture but at the cost of open procedure with significant blood loss [7].

Unstable trochanteric fractures with coronal split continue to be a challenge for orthopedic surgeons. Near-anatomical reduction and optimal positioning of implants are of paramount importance for good outcome and reducing the risk of complications [8].

The objective of our study is to hypothesize that anatomical reduction and supporting the lateral wall is important to prevent complications with an additional buttress plate along with PFN which increases the stiffness of the bone-implant construct reducing the rate of complications.

\section{Material and Methods}

After obtaining institutional review board approval, a prospective, nonrandomized study was conducted from April 2015 to December 2017 at Ashwini Sahakari Rugnalaya and Sanshodhan Kendra Solapur, India and Government medical college Chandrapur, India from April-2015 to December-2017. Thirty-two patients of unstable trochanteric fractures available for study with a mean age of 59.3 years (range: 55 - 80 years) with eighteen male and fourteen female were included in the study. The diagnosis of unstable fracture is made on radiographic appearance of fracture with the involvement of posteromedial and post- 
erolateral part of the trochanter. The CT scan was not used because of cost constraint. The AO/OTA classification was used to classify the fractures [9]. Twenty two cases of right side involvement and ten patients of left side involvements are included in the study. The comminuted unstable intertrochanteric fractures with lateral wall comminution were included in the study and very elderly morbid patients with high medical and an aesthesia risks were excluded from study.

There were 26 cases of A3 and six cases of A2 were fixed by PFN combined with trochanteric buttress plate to augment the comminuted lateral wall (Table 1).

Fall from height was the most common mode of injury, accounting for $60 \%$ of the cases in middle aged and elderly patients, with the remainder sustaining injury in road traffic accidents in younger age groups. Proximal femoral nail (nail length: $180 \mathrm{~mm}$ for A2 in six cases fractures, $240 \mathrm{~mm}$ in ten cases and long PFN for 16 cases A3 fractures) having a proximal diameter of $15 \mathrm{~mm}$, with $8 \mathrm{~mm}$ compression and $6.4 \mathrm{~mm}$ derotation screw, was used. Distal locking was carried out with a $4.9 \mathrm{~mm}$ bolt. The nail has a $6^{*}$ medio-lateral angle for easy insertion and tapered distal tip to avoid stress generation. Average delay from time of injury to fixation was three-days (range: 2 - 10 days), which was mostly due to delay inreporting to the hospital. The average follow-up period of our study was average 10.6 months ( 7 months to 16 months).

\subsection{Implant Design and Specification of Trochanteric Buttress Plate [Figures 1(a)-(d)]}

Trochanteric Buttress Plate (TBP) is designed by the first author.

It is just a $3 \mathrm{~mm}$ thick anatomically contoured malleable oblong plate with two Oblique holes angulated at 130 and 135 degrees for passing $6.4 \mathrm{~mm}$ derotation screw and $8 \mathrm{~mm}$. Hip cervical screw.

The broad heads of Derotation and Hip screws of (correct size) abuts just outside the plate being flush with lateral surface thus making fixation of bone (Head Neck) TFN/PFN and Plate a single assembly thus reinforcing fixation [Figures $1(\mathrm{a})-(\mathrm{d})]$.

The proximal portion of plate has multiple holes to accommodate $4.5 \mathrm{~mm}$ cortical screws to fix large bone piece of Greater Trochanter if feasible.

Table 1. Demographic characteristics of patients number of patients (32 hips).

\begin{tabular}{|c|c|c|c|c|}
\hline Age, & Average age & Years & & total \\
\hline \multirow{3}{*}{ Sex } & $55.3 \mathrm{yrs}$ & $55-80$ & & 32 \\
\hline & Male & Female & & \\
\hline & 18 [56.25\%] & $14[43.75 \%]$ & & 32 \\
\hline \multirow[t]{2}{*}{ Types of fracture } & A1 & A2 & A3 & \\
\hline & 0 & $6[8.75 \%]$ & 26 [81.25\%] & 32 \\
\hline \multirow[t]{2}{*}{ Location } & Right hip & Left hip & & \\
\hline & 22 [68.75\%] & $10[11.25 \%]$ & & 32 \\
\hline
\end{tabular}




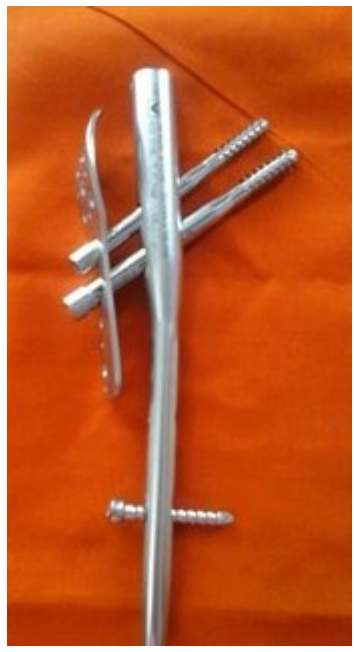

(a)

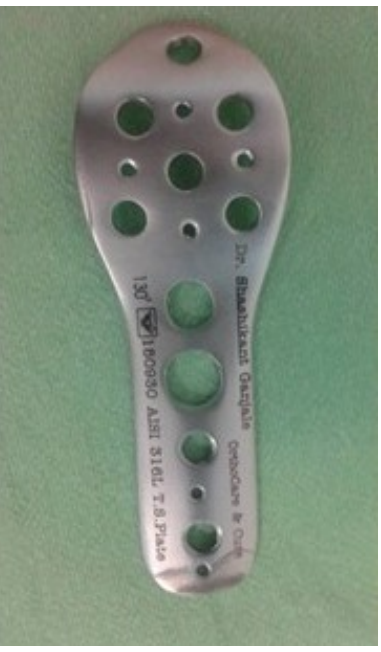

(b)

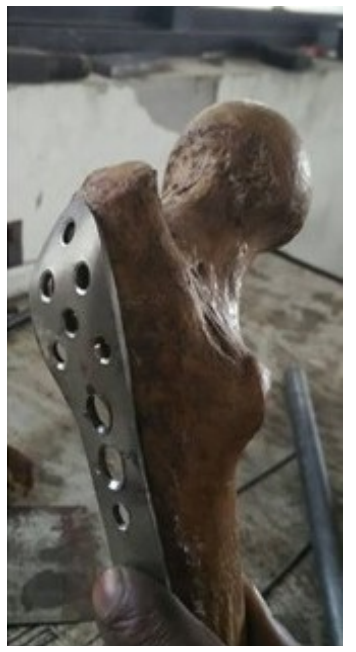

(c)

Figure 1. Plate description. (a) Trochanteric buttress plate; (b) PFN with Trochanteric buttress plate; (c) trochanteric buttress plate mounted on proximal femur.

The proximal holes can be used to secure abductors in case of small pieces of GT by tying in holes. The distal portion of plate has again two $4.5 \mathrm{~mm}$ holes for unicortical fixation of plate to upper portion of proximal femur.

The whole assembly has good rigid fixation and buttressing effect on lateral wall.

\subsection{Operative Procedure [Figures 2(a)-(f)]}

After anesthesia all cases were primarily screened under $\mathrm{c}$ arm to check the reduction in AP and lateral views on the fracture table.

Temporary fixation of fracture with $3 \mathrm{~mm} \mathrm{k}$ wire was used to fix the intertrochanteric fracture anteriorly to prevent loss of reduction. The entry was made with awl or thick pin and later enlarged with starting cannulated reamer. Guide wire was passed from entry in to canal and checked under $C$ arm for its placement.

Reaming of canal was done in patients having narrow medullary canal to fitlargest possible diameter nail in the canal.PFN of $18 \mathrm{~cm}$ or $24 \mathrm{~cm}$ in A2 fracture and Long PFN in A 3 fracture as per case was used in cases. The nail is passed over guide wire. The holes in PFN were aligned in the direction of neck properly just above the calcar.

The plate was slided through the incision taken for passing Hip screw and derotation screw, with gentle subperiosteal dissection up to trochantericflare. At times it needed extension of incision for fixing large bony piece of Greater trochanter with cortical screws. The guide wire sleeve is targeted through the jig into the corresponding holes of TBP and guide wire is passed in to neck and head of femur.

The placement of guide wire was checked under $\mathrm{c}$ arm in AP and lateral views and later drilled and fixed with corresponding screws. As the head neck Screws 


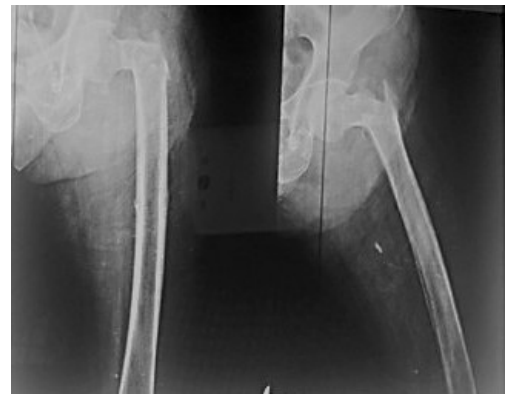

(a)

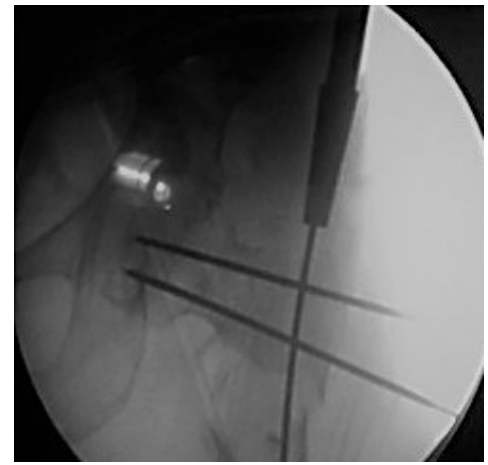

(c)

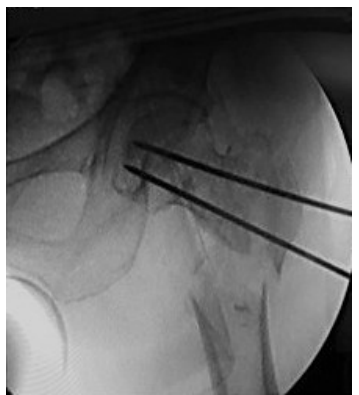

(b)

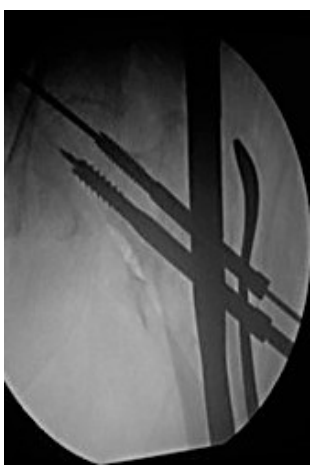

(d)

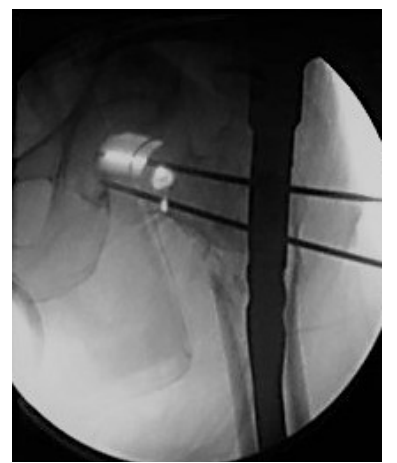

(e)

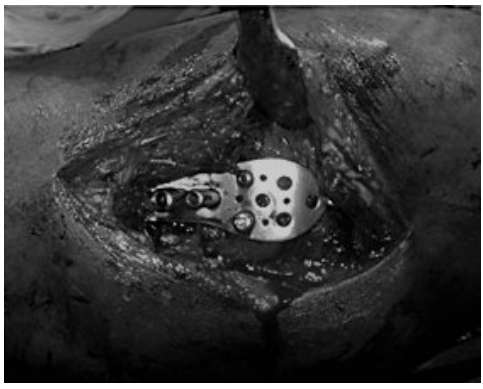

(g)

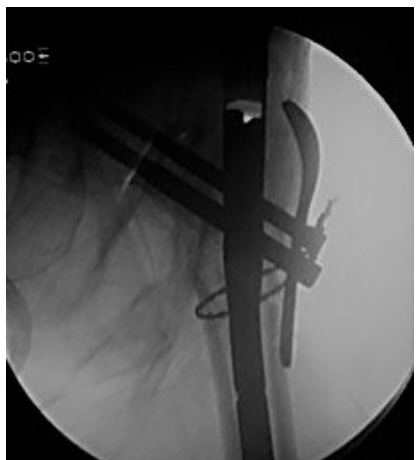

(f)

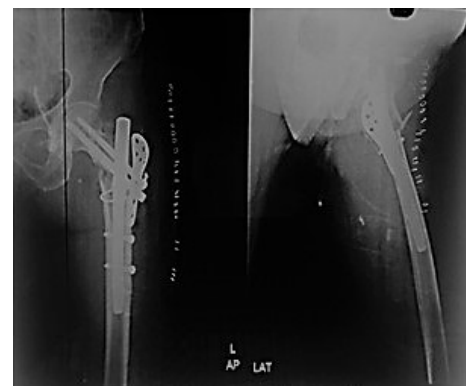

(h)

Figure 2. (a) X-ray showing unstable four part fracture femur [A3] in a $72 \mathrm{yr}$ male; (b) reduction and temporary fixation of floating trochanter with $3 \mathrm{~mm}$ k-wires; (c) entry medial to tip of the trochanter and guide wire insertion; (d) insertion of pfn through medial to the tip of the trochanter; (e) insertion of PFN with compression and stabilizing screw through trochanteric buttress plate; (f) fixation of the plate the trochanter; (g) fixation of trochanteric buttress plate with screw and anchorage of abductors to plate by sutures; (h) X ray showing final fixation of PFN with Buttress plate. 
of perfect length were tightened the buttressing effect of TBP over lateral wall was evident thus making fixation more rigid. The two inferior holes in the plate below the head neck screws were fixed unicortically or at times we could get bicortical fixation occasionally depending on the thickness of shaft at that level. In three cases, greater trochanter was found in big chunk of piece, was fixed with cortical screws through the trochanteric buttress plate. In the five cases greater trochanteric bone was found in smaller pieces they were collectively sutured back to the holes in the trochanteric buttress plate thus securing abductor muscles. In the three cases plate was secured with supplementary cerclage wire. In the initial phase of study we encountered difficulties in sliding and contouring the plate as per trochanteric which we learn subsequently. In cases if long PFN was used, distal interlocking was done by free hand technique under c-arm control.

The vacuum drain was kept and wound closed in layers for 24 hours. Intraoperative details like operative time, blood loss, and number of blood units transfused were recorded. The sponge mops were soiled with blood and vacuum drainage kept for 24 hours was used for calculation of blood loss. The patients were encouraged to sit in bed and perform static exercises with the affected limb on the next day of operation. An X-ray examination was performed on the second postoperative day. At around 10th day postoperatively, the stitches were removed. Touchdown weight bearing with the help of a walker or crutches began two weeks after the surgery. One month after the surgery, progressive weight bearing and full weight bearing, three months after surgery, based on the evidence of stability

\section{Results}

Postoperative X-ray examination showed anatomical reduction in 28 cases, (87.5\%) and acceptable reduction in four cases. The tip-apexdistance of the femoral neck screw less than $20 \mathrm{~mm}$ was achieved in all the patients. The clinico-radiological consolidation of the fracture was observed in all cases at an average of 12.6 weeks ( 12 - 18 weeks). Mean duration of surgery was 75 min (45 $80 \mathrm{~min}$ ) in all the patients. Mean intraoperative blood loss was $180 \mathrm{~mL}$ (110 $220 \mathrm{~mL}$ ) and mean postoperative drainage in first 48 hours was an average 80 $\mathrm{mL}$ [60 to $110 \mathrm{ml}$.] Patients with less than $10 \mathrm{gm} \%$ of hemoglobin received blood transfusion. In our series, 26 patients had hemoglobin between 6 and10 gm, therefore transfusion was required in the majority of cases. There were some lo$\mathrm{cal}$ as well as some systemic complications. Four patients developed local complications including lateral migration of neck screws $(\mathrm{n}=2)$, infection $(\mathrm{n}=2)$, No case of nonunion or implant breakage was observed. Three of the patients complained of persistent pain in the hip region because of impingement of the proximal screw which was scheduled for hardware removal. Two patients had moderate persistent pain due to varusmalunion. The average sliding of the screws of PFN in this study was observed to be $2.8 \mathrm{~mm}(2-5 \mathrm{~mm})$. Cases with 
good anatomical reduction and fixation did not have limb length discrepancy. Four cases had less than anatomical reduction observed in the immediate postoperative period resulting in $6-7 \mathrm{~mm}$ of shortening, but none of these cases required a shoe raise. Identifiable rotation of the proximal fragment on X-rays was not observed in any of our cases [Figures 3(a)-(d) and [Figures 4(a)-(d) and Figures 5(a)-(d)].

The average scoring of our patients according to Salvati and Wilson criteria was 34 to 36 in twenty eight patient [87.5\%] and 22to 24 in two patients [6.25\%] and 20 in two patients [6.25\%]. Normal walking was resumed in 28 patients, four patients needed a walking aid for long distances. The excellent results are in 28 patients, good in two patients and fair in two patients. The excellent to good results are seen in $93.75 \%$ [ 30 patients] in our series.

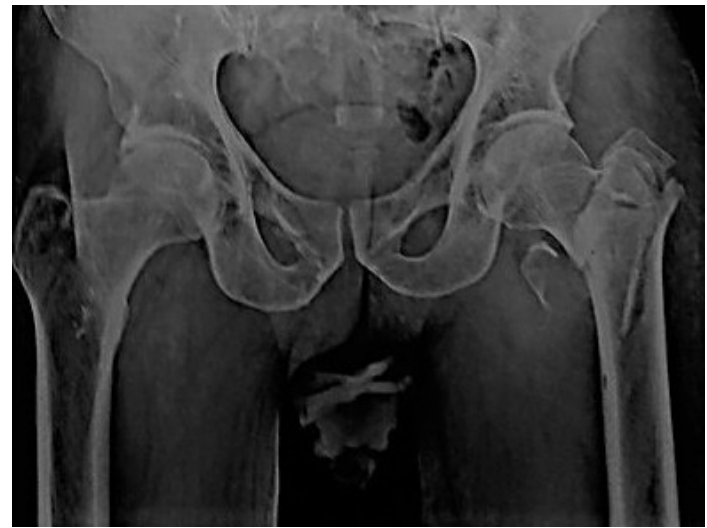

(a)

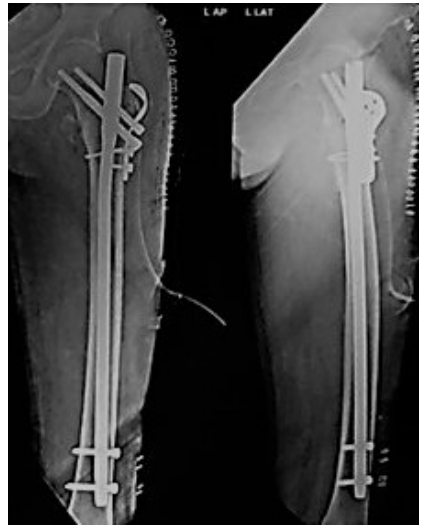

(b)

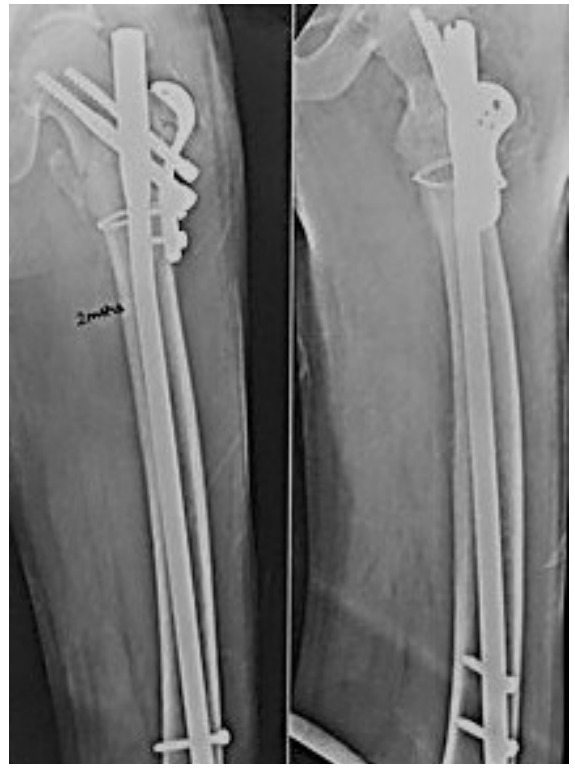

(c)

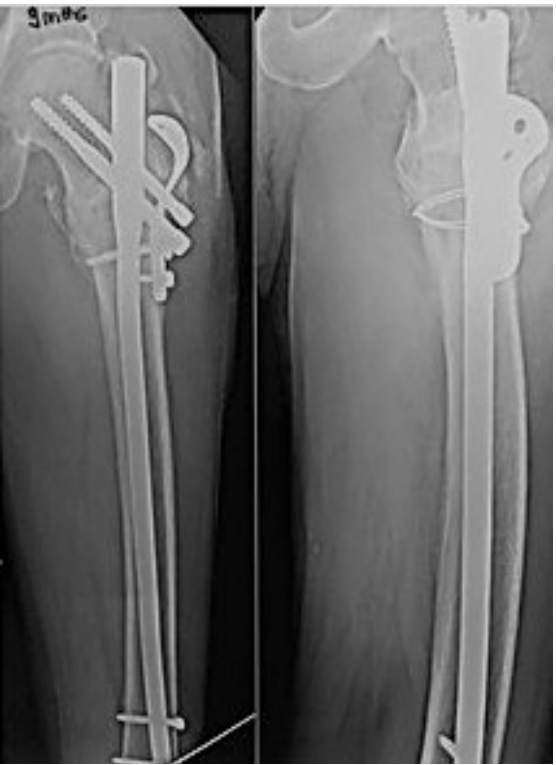

(d)

Figure 3. (a) X-ray showing unstable four part trochanteric fracture [A3] in $67 \mathrm{yr}$ old female; (b) post op X-ray showing anatomical reduction and fixation by PFN with buttress plate; (c) X-ray after two months reduction is maintained; (d) X-ray after six months follow-up. Fracture united with good radiological and functional outcome. 


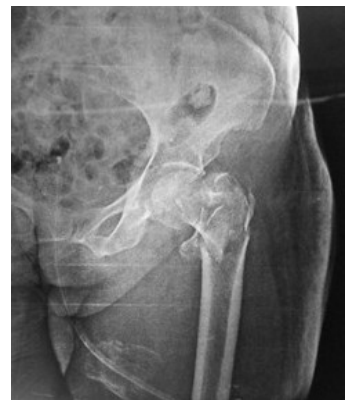

(a)

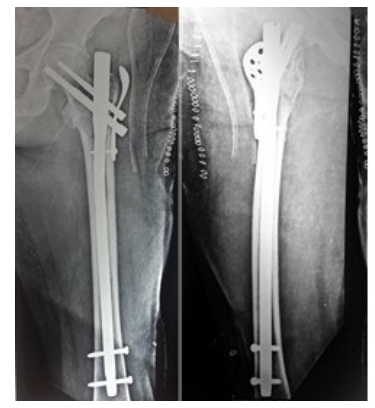

(b)

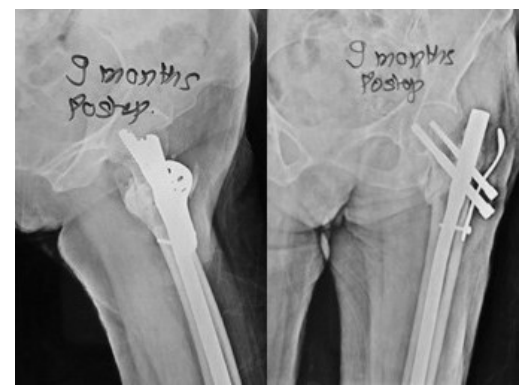

(c)

Figure 4. (a) X-ray showing unstable four part trochanteric fracture [A3] in $55 \mathrm{yr}$ old male; (b) post op X-ray showing anatomical reduction with supplementary cerclage wire and fixation by PFN with buttress plate; (c) X-ray after 10 months follow-up. Fracture united with good radiological and functional outcome.

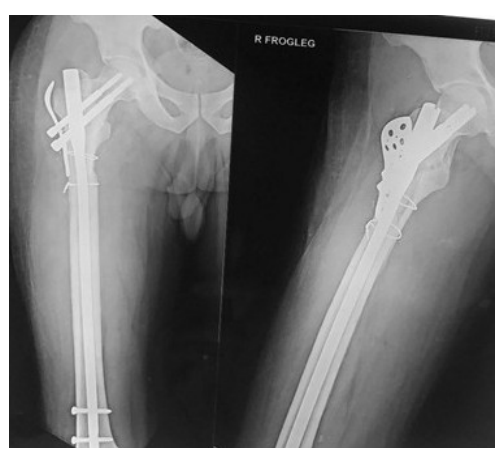

(a)

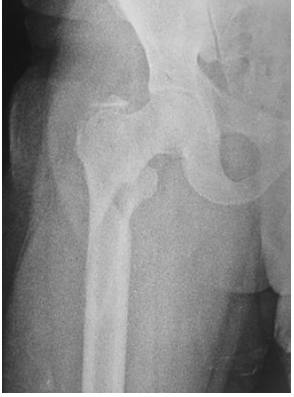

(b)

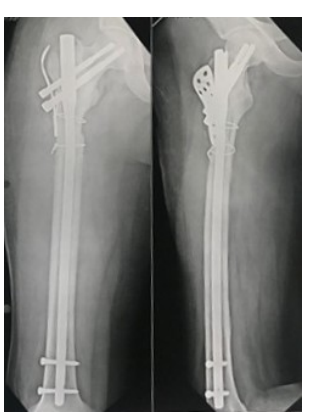

(c)

Figure 5. (a) X-ray showing unstable four part trochanteric fracture [A3] in $55 \mathrm{yr}$ old male; (b) post op X-ray showing anatomical reduction with supplementary cerclage wire and fixation by PFN with buttress plate; (c) X-ray after 10 months follow-up. Fracture united with good radiological and functional outcome. 


\section{Discussion}

In an unstable trochanteric fractures, intramedullary devices have an advantage of being load sharing with smaller bending moments allowing early weight bearing and preventing excessive fracture collapse [10] [11]. However important complications include lateral protrusion of screws, cut through of screws, Zor reverse $\mathrm{Z}$ effect, and the fracture of lateral trochanteric wall [12].

Recent workers stated that the lateral femoral wall was found to be the main predictor for a reoperation after an intertrochanteric fracture [1] [2]. We are of the opinion that in PFN surgery also lateral wall instability is important as it is in DHS fixation. Though intramedullary nailing is favored by recent literature, failure rate of gamma nail for the treatment of these fractures ranges from 12.7\% to $15 \%$ [13]. Fogagnolo et al., showed a complication rate of about $23.4 \%$ with the use of PFN in the treatment of an unstable trochnateric fractures [14]. The proximal femoral nail used in another study done by Uzun et al. reported $5.7 \%$ nonunion, secondary varus collapse in $25.7 \%$, cutout of proximal screws in $5.7 \%$ and reoperation in $14.3 \%$ cases which has considerably affected functional results [15].

Antirotation (PFNA) in the treatment of these unstable intertrochanteric fractures is also controversial with varying results, though they have some theoretical advantage over the DHS in osteoporotic bone. Various authors have shown high complication rate with the use of these implants. Takigami et al. in there study showed complications in $14 \%$ of the cases and $4 \%$ required reoperation after use of PFNA [16]. Proximal femoral nail compensates for posteromedial defect acting as buttress to prevent medialization but fails to provide stability on lateral side if lateral wall is compromised. The varus collapse occurs even after fixation of trochanteric fracture by Intramedullary nail as comminuted intertrochanteric fractures of femur are difficult to fix more so when there is coronal split fracture. It is also reported by some workers the mismatch between Indian femora with pfna 2 [17].

To prevent varus collapse invariably as lateral wall fails to provide enough support to the implant so we need an implant design being able to support and fix the lateral wall, then it may decrease implant failure. Hence restoration of lateral wall is of paramount importance to prevent varus collapse and further complications. Babst et al. reported significant reduction in excessive collapse and subsequently reduced limb length discrepancy by using a TSP in combination with the DHS but it is invasive method with significant blood loss in comparison with our method of minimally invasive method with significant superior results [18].

More recently, locking plates especially designed for the proximal femur, PF-LCP have become available especially for the management of complex trochanteric fractures. PF-LCP acts as a fixed angle internal fixator device and achieves greater stability compared with DHS/DCS/Angle blade plate while avoiding excessive bone removal. PF-LCP is ideal in such fractures [19]. It acts 
as a buttress and prevents excessive fracture collapse. It substitutes for an incompetent lateral cortex, however complications occurred in $31.3 \%(n=5)$ in medium-term follow-up after PF-LCP in proximal unstable inter- and subtrochanteric femur fractures [20].

Proximal femoral locking plates are associated with a high complication rate, frequently requiring revision or secondary surgeries in the treatment of unstable proximal femur fractures. Given the high complication rate with PFLPs, careful attention to reduction, use of a PFLP implant, and consideration should be given to alternative implants or fixation techniques when appropriate [21].

Babhulkar et al. reported recently Augmentation of intramedullary nailing in unstable intertrochanteric fractures using cerclage wire and lag screws in unstable trochanteric fracture for lateral wall reconstruction was used to reduce the complications associated with lateral wall fracture [22]. The procedure has provided good radiological and functional outcome in there series. However the procedure requires little additional operating time to reconstruct lateral wall with cerclage wire. To augment trochanter with cerclage wire is difficult procedure and may require additional dissection of soft tissues and loosening of wire is possible complication.

Recently a closed method of IM Nail and screw augmentation was described encouraging results. Author believes that improved bony contact between proximal and distal fragments by stabilization of the comminuted lateral wall is likely to improve the chances of union and maintenance of adequate lever arm [8]. However this method is not useful when the trochanter is fragmented.

We believe that the lateral wall reconstruction by newly designed plate significantly lessened the incidence of lateralization of the greater trochanter with limited telescoping of comminuted fragments following weight bearing. If there is coronal split of lateral wall the head neck screws can penetrate in up to the nail even after reinforcement with encirclage wire [Figure 6(a) and Figure 6(b)]. It enhances the fixation strength of proximal femoral nail even in coronal spilt fracture. In unstable intertrochanteric fractures the integrity of the lateral femoral wall can be restored with augmentation of PFN with an additional lateral wall supporting plate to prevent complications.

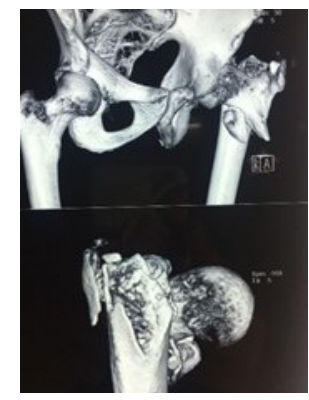

(a)

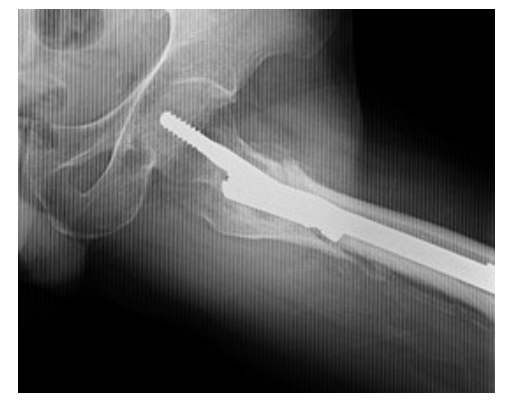

(b)

Figure 6. (a) 3D ct scan showing fracture multifragmented trochanter fracture; (b) the coronal plane fractures of greater trochanter cause penetration of head and neck screws in through the split fracture of lateral wall. 
In our study, varusangulations of more than $5^{\circ}$ was noted in 4 patients. In our study z effect was not noted because of reconstruction of lateral wall. No case of screw cutout was noted in our series as compared in literature where cut out of screw is reported up to $2.5 \%$. In two cases there was lateral migration of screws may be this protrusion is most likely because of the shearing force caused by the tendency for a lateral displacement of the proximal end and a medial displacement of the distal end in unstable fractures osteoporotic bone. The average sliding of the DHS in study of Gupta et al. was observed to be $3.4 \mathrm{~mm}$ in unstable fractures treated by DHS with trochanteric stabilization plate. In our study average sliding of screw was found to be $2.8 \mathrm{~mm}$.

Excessive fracture collapse results in shortening of the abductor lever arm. This leads to permanent limping and increases morbidity after fixation of extramedullary implants which is not seen our series. In our study, only 2 patients who had $>15 \%$ of fracture collapse scored "Fair" at 24 weeks. This shows the importance of preventing excessive fracture collapse in order to improve the final clinical outcome. In case of severe osteoporosis that interferes with proximal screw fixation screws augmented with cement may be used to increase stability as suggested by Alexa [23].

In place cement augmentation an additional plate effectively prevents the rotation of the proximal fragment and fracture collapse. Healing time of 14.2 weeks. The functional results In this study were graded as excellent in 26 of the cases and good in 6 of the cases and no case was in the category of poor according to the Salvati and Wilson scoring system.

In our series complications are less as comparable to the technical and mechanical complications described in literature [8] [14] [22] [24] [25]. Our findings indicate that the use LATERAL PLATE beneficial in restoring anatomy of proximal femur which prevents loosening of screws and helps in union. Within the first year, we found excellent to good results in an unstable trochanteric fracture.

The shortcoming of our study is that the mechanism of action of the PFN with plate has not been evaluated in biomechanical studies. Further biomechanical and clinical studies are necessary to validate the efficacy of PFN augmentation with plate.

\section{Conclusion}

Augmentation of PFN with the trochanteric buttress plate creates a biomechanically stable construct by incorporating the comminuted trochanter and restores the proximal femoral anatomy, ensuring significant reduction in excessive collapse and subsequently reduced limb length discrepancy. The superior functional and radiological outcomes in patients with unstable trochanteric fractures are observed in our series.

\section{Ethical Consideration}

No conflict of interest in this study. 
Hospital ethical committee approved the study design.

\section{References}

[1] Gotfried, Y. (2004) The Lateral Trochanteric Wall: A Key Element in the Reconstruction of Unstable Pertrochanteric Hip Fractures. Clinical Orthopaedics and Related Research, 425, 82-86. https://doi.org/10.1097/01.blo.0000132264.14046.c2

[2] Gupta, R.K., Sangwan, K., Kamboj, P., Punia, S.S. and Walecha, P. (2010) Unstable Trochanteric Fractures: The Role of Lateral Wall Reconstruction. International Orthopaedics, 34, 125-129. https://doi.org/10.1007/s00264-009-0744-y

[3] Adams, C.I., Robinson, C.M., Court-Brown, C.M., et al. (2001) Prospective Randomized Controlled Trial of an Intramedullary Nail versus Dynamic Screw and Plate of Intertrochanteric Fracture of the Femur. Journal of Orthopaedic Trauma, 15, 394-400. https://doi.org/10.1097/00005131-200108000-00003

[4] Bendo, J.A., Weiner, L.S., Strauss, E., et al. (2004) Collapse of Intertrochanteric Hip Fractures Fixed with Sliding Screws. Orthopedic Reviews, No. 425, 30-37.

[5] Asif, N., Owais, S.A., Qureshi, A., Jilani, L.Z., Hamesh, T. and Jameel, T. (2016) Unstable Intertrochanteric Fracture Fixation-Is Proximal Femoral Locked Compression Plate Better than Dynamic Hip Screw. Journal of Clinical and Diagnostic Research, 10, RC09-RC13.

[6] Jonnes, C., Shishir, S.M. and Najimudeen, S. (2016) Type II Intertrochanteric Fractures: Proximal Femoral Nailing (PFN) versus Dynamic Hip Screw (DHS). The Archives of Bone and Joint Surgery, 4, 23-28.

[7] Koyuncu, Ş., Altay, T., Kayalı, C., Ozan, F. and Yamak, K. (2015) Mechanical Failures after Fixation with Proximal Femoral Nail and Risk Factors. Clinical Interventions in Aging, 10, 1959-1965.

[8] Gadegone, W.M., Shivashankar, B., Lokhande, V. and Salphale, Y. (2017) Augmentation of Proximal Femoral Nail in Unstable Trochanteric Fractures. SICOT.

[9] Kellam, J.F., Meinberg, E.G., Agel, J., Karam, M.D. and Roberts C.S. (2018) Introduction: Fracture and Dislocation Classification Compendium-2018: International Comprehensive Classification of Fractures and Dislocations Committee. Journal of Orthopaedic Trauma, 32, S1-S10.

[10] Salvati, E.A. and Wilson, P.D. (1973) Long Term Results of Femoral Head Replacement. The Journal of Bone and Joint Surgery. American Volume, 55A, 516-524. https://doi.org/10.2106/00004623-197355030-00007

[11] Soni, M., Anand, V., Sikdar, J., Singh, R., Sidhu, V. and Goyal, C. (2015) Comparative Study of Proximal Nailing versus Dynamic Hip Screw Device in the Surgical Management of Intertrochanteric Fractures. Clinical Orthopaedics and Trauma, 6, 71.

[12] Gadegone, W.M. and Salphale, Y.S. (2010) Short Proximal Femoral Nail Fixation for Trochanteric Fractures. Journal of Orthopaedic Surgery (Hong Kong), 18, 39-44. https://doi.org/10.1177/230949901001800109

[13] Gadegone, W.M. and Salphale, Y.S. (2007) Proximal Femoral Nail-An Analysis of 100 Cases of Proximal Femoral Fractures with an Average Follow up of 1 Year. International Orthopaedics, 31, 403-408. https://doi.org/10.1007/s00264-006-0170-3

[14] Megas, P., Kaisidis, A., Zouboulis, P., Papas, M., Panagopoulos, A. and Lambiris, E. (2005) Comparativestudy of the Treatment of Pertrochanteric Fractures-Trochanteric Gamma Nail vs. Proximal. Femoral Nail. Zeitschrift Fur Orthopadie Und Ihre Grenzgebiete, 143, 252-7. https://doi.org/10.1055/s-2005-836453 
[15] Fogagnolo, F., Kfuri Jr., M. and Paccola, C. (2004) Intramedullary Fixation of Pertrochanteric Hip Fractures with the Short AO-ASIF Proximal Femoral Nail. Archives of Orthopaedic and Trauma Surgery, 124, 31-37. https://doi.org/10.1007/s00402-003-0586-9

[16] Uzun, M., Erturer, E., Ozturk, I., Akman, S., Seckin, F. and Ozcelik, I.B. (2009) Long Term Radiographic Complications Following Treatment of Unstable Intertrochanteric Femoral Fractures with Proximal Femoral Nail and Effects on Functional Results. Acta Orthopaedica et Traumatologica Turcica, 43, 457-463.

[17] Takigami, I., Matsuoto, K., Ohara, A., Yamanaka, K., Naganawa, T. and Ohashi, M. (2008) Treatment of Trochanteric Fractures with PFNA Nails System-Report of Early Results. Bulletin of the NYU Hospital for Joint Diseases, 66, 276-279.

[18] Hu, S.-J., Chang, S.-M., Ma, Z., Du, S.-C., Xiong, L.-P. and Wang, X. (2016) PFNA-II Protrusion over the Greater Trochanter in the Asian Population Used in Proximal Femoral Fractures. Indian Journal of Orthopaedics, 50, 641-646.

[19] Babst, R., Renner, N., Biedermann, M., Rosso, R., Hebere, M., Harder, F. and Regazzoni, P. (1998) Clinical Results Using the Trochanter Stabilizing Plate (TSP): The Modular Extension of the Dynamic Hip Screw (DHS) for Internal Fixation of Selected Unstable Intertrochanteric Fractures. Journal of Orthopaedic Trauma, 12, 392-399. https://doi.org/10.1097/00005131-199808000-00005

[20] Lee, W.T., Murphy, D., Kagda, F.H.Y. and Thambiah, J. (2014) Proximal Femoral Locking Compression Plate for Proximal Femoral Fractures. Journal of Orthopaedic Surgery, 22, 287-293. https://doi.org/10.1177/230949901402200304

[21] Hodel, S., Beeres, F.J.P., Babst, R. and Link, B.C. (2017) Complications Following Proximal Femoral Locking Compression Plating in Unstable Proximal Femur Fractures: Medium-Term Follow-Up. European Journal of Orthopaedic Surgery \& Traumatology, 27, 1117-1124. https://doi.org/10.1007/s00590-017-1981-1

[22] Wirtz, C., Abbassi, F., Evangelopoulos, D.S., Kohl, S., Siebenrock, K.A. and Krüger, A. (2013) High Failure Rate of Trochanteric Fracture Osteosynthesis with Proximal Femoral Locking Compression Plate. Injury, 44, 751-756. https://doi.org/10.1016/j.injury.2013.02.020

[23] Kulkarni, S.G., Babhulkar, S.S., Kulkarni, S.M., Kulkarni, G.S., Kulkarni, M.S. and Patil, R. (2017) Augmentation of Intramedullary Nailing in Unstable Intertrochanteric Fractures Using Cerclage Wire and Lag Screws: A Comparative Study. Injury, 48, S18-S22.

[24] Alexa, O. and Cozma, T. (2004) Compression Hip Screw Fixation with Bone Cement in Trochanteric Fractures. Revista Medico-Chirurgicala a Societatii De Medici Si Naturalisti Din Iasi, 108, 416-419.

[25] Palm, H., Jacobsen, S., Sonne-Holm, S. and Gebuhr, P. (2007) Hip Fracture Study Group. Integrity of the Lateral Femoral Wall in Intertrochanteric Hip Fractures: An Important Predictor of a Reoperation. The Journal of Bone and Joint Surgery. American Volume, 89, 470-475. 